compared with 1.6 to $1.7 \mathrm{~km} \mathrm{~s}^{-1}$ for the overlying sediments) which has been mapped in many other regions of the Red Sea. But an even more interesting correlation can be made outside the area. Ross and his colleagues find that the Red Sea evaporites, dated by fossils in the interbedded shales, are of the same age as those previously discovered by deep drilling in the Mediterranean. They thus equate the age of the Red Sea reflector $S$ with that of the Mediterranean reflector $M$.

The correlation of the evaporite surface with the widespread reflector $S$, backed up by direct access by drilling at other sites, implies that most of the Red Sea is underlain by late Miocene evaporites, the chief exception being the central rift valley. Ross et al. also find that the depth of the reflector $S$ coincides with the depth of the brine interface in the Atlantis II Deep. This leads them to suggest that an occurrence of brine is possible wherever the evaporite outcrops in the vicinity of an enclosed basin and thus to predict the presence of other brine pools in the Red Sea. At the time that Ross and his colleagues were preparing their report, evidence for brine pools outside the Atlantis II area was scanty; but before the-report had appeared, Backer and Schoell (Nature Physical Science, 240, 153 ; 1972) had already reported the discovery of no less than thirteen new brine pools.

The widespread accurrence of late Miocene evaporites in the Red Sea also has important implications for seafloor spreading in the area. The evaporites are apparently absent from the central rift valley, but the new drill hole at site 227 showed that rocks as old as or older than Miocene occur within 1 to $3 \mathrm{~km}$ of what is thought to be an actively spreading ridge. This would seem to destroy the idea that spreading in the Red Sea has been continuous since a supposed beginning during the Tertiary. The most reasonable conclusion based on the data from site 227 is that the present phase of spreading began less than two million years ago following a hiatus which may have lasted since the early Miocene.

The other principal Red Sea theme is, of course, the occurrence of mineral deposits within the sediments. At site 225 , dark shales were found to contain over 5 per cent iron, about 1,000 p.p.m. vanadium and about 500 p.p.m. molybdenum. Thin shale layers within the evaporite also contained 200 p.p.m. copper. Drilling at site 226 in the Atlantis II Deep was not entirely successful because of the presence of a shallow impenetrable layer of basalt. These basalts were mineralogically similar to deep oceanic tholeiites. Their metal contents were not significantly different from those of other basalts; but $14 \mathrm{~m}$ of sediments enriched in heavy metals were recovered from above the basalt layer, and these may continue beneath. Site 227 (about $3 \mathrm{~km}$ east of the end of the Atlantis II Deep) also produced shale layers rich in vanadium and molybdenum, and copper concentrations were as high as 700 p.p.m. Ross and his colleagues suggest that these sediments could be the source of the metals in the hot brine deposits.

Site 228 , near the axial valley but well away to the south-east of the Atlantis II Deep, gave sediment sequences similar to those at 225 and 227. Anhydrite was reached at a depth of $280 \mathrm{~m}$ but problems led to the abandonment of the hole before halite was reached. Ross et al. conclude, however, that halite lies within a few tens of metres from the bottom of hole 228. At sites 225 and 227 , the salinity of the interstitial waters in the sediment was found to increase on approach to the evaporites to a value fairly close to that of a saturated sodium chloride solution. The assumption that a similar phenomenon applies in the vicinity of site 228 allowed the prediction of the depth of the halite. But perhaps of greater importance was the discovery of black shales containing high concentrations of zinc in the range 0.5 to 5.0 per cent. Thus in the Red Sea there are at least two suites of metalliferous shales-one enriched in vanadium and molybdenum and the other in zinc.

\section{ELEMENTARY PARTICLES}

\section{Hiatus Ahead}

RECENT measurements at CERN confirm that the probability of interaction of a proton with another proton increases with energy up to at least $1,500 \mathrm{GeV}$. This could have serious implications for the Pomeranchuk theorem, one of the central tenets of high energy physics, which predicts that the probability (or cross-section) of proton-proton interactions will be almost the same as, or slightly less than, the cross-section for interactions between protons and antiprotons.

But the evidence so far indicates that the cross-section of the proton-antiproton interaction declines as the energy increases, certainly up to 50 $\mathrm{GeV}$, the present limit of measurement. Unless this cross-section begins to increase with energy quite suddenly at above $50 \mathrm{GeV}$ the inescapable conclusion is that the Pomeranchuk theorem is seriously contravened at energies of a few hundred $\mathrm{GeV}$-in other words, the Pomeranchuk theorem is threatened because an extrapolation of existing data strongly suggests that the proton-proton cross-section is much higher than the proton-antiproton cross-section at high energies.

This concern about the validity of the Pomeranchuk theorem arises from two

\section{Movement of Atmospheric Carbon Dioxide}

THE variations in carbon dioxide levels in the atmosphere with the changing season is a subject of wide interest. Until recently, however, few data were available for the Southern Hemisphere; but in 1972 the CSIRO Division of Atmospheric Physics began a monitoring programme based on the collection of samples by aircraft. In next Monday's Nature Physical Science (March 26) Garratt and Pearman present the first results of this programme, which cover the period May 1972 to February 1973.

Most of the samples were collected by aircraft over the sea to the south-east of Australia, and these include samples collected on the same day (or within a few days) from two or more levels in the middle and upper troposphere. From June to September, there was an average increase of $\mathrm{CO}_{2}$ content with height of 0.4 p.p.m. between 4 and $10 \mathrm{~km}$, suggesting downward transfer of $\mathrm{CO}_{2}$; between November and February (summer) there was a similar decrease with altitude, suggesting upward transfer (see figure). These patterns can be correlated with changes in the surface temperature of the sea, which decreased from May to September and increased between November and February, at an average rate of $1^{\circ} \mathrm{C} \mathrm{a}$ month in each case.

Colder water has a greater capacity to dissolve $\mathrm{CO}_{2}$ than warmer water, so these results fit into the pattern which might have been expected, namely that gas is dissolved and then given up. This Southern Hemisphere, at least at middle latitudes, thus explaining the seasonal variations of the $\mathrm{CO}_{2}$ gradient from the ocean surface to the tropopause.

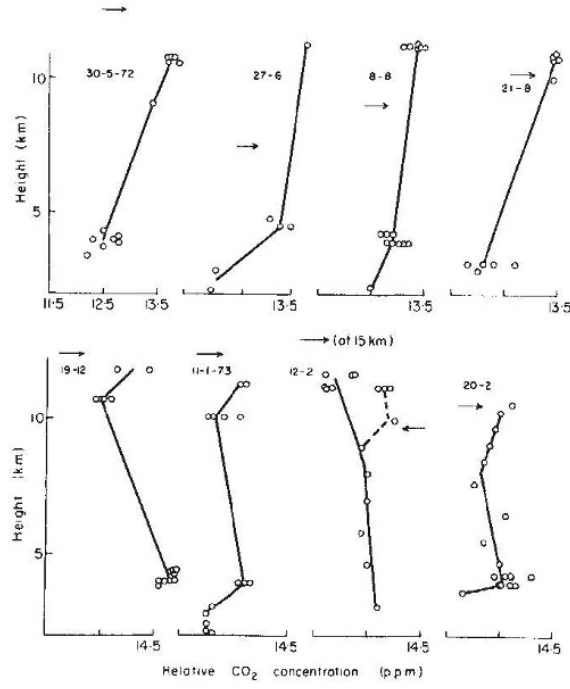

Typical measurements of $\mathrm{CO}$, concentration at different altitudes southeast of Australia. The dates of the measurements are included ; the level of the tropopause is marked by an arrow in each case. presumably applies throughout the 